NBER WORKING PAPER SERIES

COST-SHARING AND PRODUCTIVITY

Teresa B. Gibson

A. Mark Fendrick

Michael E. Chernew

Working Paper 18402

http://www.nber.org/papers/w18402

\author{
NATIONAL BUREAU OF ECONOMIC RESEARCH \\ 1050 Massachusetts Avenue \\ Cambridge, MA 02138 \\ September 2012
}

Funding for this study was provided by Pfizer Inc. to Truven Health Analytics (formerly Thomson Reuters Healthcare). All opinions expressed are those of the authors. We thank Amanda Farr, MPH for research and programming assistance. The views expressed herein are those of the authors and do not necessarily reflect the views of the National Bureau of Economic Research.

At least one co-author has disclosed a financial relationship of potential relevance for this research. Further information is available online at http://www.nber.org/papers/w18402.ack

NBER working papers are circulated for discussion and comment purposes. They have not been peerreviewed or been subject to the review by the NBER Board of Directors that accompanies official NBER publications.

(C) 2012 by Teresa B. Gibson, A. Mark Fendrick, and Michael E. Chernew. All rights reserved. Short sections of text, not to exceed two paragraphs, may be quoted without explicit permission provided that full credit, including (C) notice, is given to the source. 
Cost-Sharing and Productivity

Teresa B. Gibson, A. Mark Fendrick, and Michael E. Chernew

NBER Working Paper No. 18402

September 2012, Revised October 2012

JEL No. I11,I18

\begin{abstract}
A growing body of literature examines the cross price elasticities between different health care services. For example, increasing the patient out of pocket price for some health care services increases the utilization of other health care services. Yet, the literature has generally ignored the connection between cost sharing for health care services and labor market outcomes. This paper examines the direction and magnitude of the reduced form relationship between patient cost-sharing and work loss following methods used to study the impact of cost-sharing and medical spending, finding a positive, quantitatively meaningful association between cost-sharing and hours absent. We find no such association between cost-sharing and the probability of incurring short-term disability days. This suggests that the cross-market ramifications of higher patient cost sharing extend beyond other health care services to include broad labor market outcomes.
\end{abstract}

Teresa B. Gibson

Truven Healthcare Analytics, Inc.

777 E. Eisenhower Parkway

Ann Arbor, MI 48108 USA

teresa.gibson@truvenhealth.com

A. Mark Fendrick University of Michigan

300 NIB, 7E14

Ann Arbor, Michigan 48109-0429

amfen@umich.edu
Michael E. Chernew

Harvard Medical School

Dept. of Health Care Policy

180 Longwood Avenue

Boston, MA 02115

and NBER

chernew@hcp.med.harvard.edu 
Introduction

In 2010, almost 100 million individuals received insurance coverage through employersponsored health plans offered by large and medium sized firms in the United States (Garrett and Buettgens 2011). Employers therefore exercise considerable control over the features of insurance plans. For example, there can be significant variation across employers in the structure and amount of out-of-pocket cost sharing requirements that the employees face when they use care. For example, because of variation in the number of tiers in a formulary, and placement of drugs on those tiers, the copayment charged to employees for any given prescription could range across employers from $\$ 0$ to over $\$ 90$ (Kaiser Family Foundation/HRET 2011). Moreover, over the past several years, employers have been increasing cost sharing requirements including copayments for medications in an effort to control spending. For covered workers with three or four-tier prescription drug cost sharing, average copayments for generics rose from $\$ 8$ in 2007 to \$11 in 2011, and preferred brand name medications rose from \$15 to \$25 (Kaiser Family Foundation/HRET 2011).

Extensive literature examines the ramifications of these employer decisions, focusing largely on the effects of patient cost-sharing (i.e., copayments, coinsurance) for prescription medications on health care utilization of health care services. The literature is dominated by studies of the direct effects of variation in cost sharing (e.g., the impact of higher prescription drug copays on use of prescription drugs) (Goldman, Joyce et al. 2004; Gibson, Ozminkowski and Goetzel 2005). While the effects vary across medication classes and patient groups, for the most part, higher levels of prescription drug cost-sharing have been associated with lower levels of medication utilization and adherence. A growing body of literature examines the cross price elasticities 
between cost sharing for some services and the utilization of others (e.g., the impact of cost sharing for prescription drugs on hospitalizations, complications, emergency department visits, and medical spending) (Chandra, Gruber and McKnight 2010; Goldman, et al. 2004; Gibson, Ozminkowski and Goetzel 2005; Afendulis et al., 2011). Generally, the evidence supports the connections between markets, which is interpreted largely as a health effect: adhering to medications that treat chronic disease prevents adverse events that lead to use of more expensive services.

Yet, because health care data is generally segregated from other types of employer data, the literature has generally ignored the connection between use of health care services and labor market outcomes. In general, adverse events and poor health status can lead to higher spending on expensive healthcare services, as well as missed time at work and reduced productivity (Carls et al. 2012; Loeppke et al. 2011; Gibson, et al. 2010).

Our aim is to examine the direction and magnitude of the reduced form relationship between cost-sharing and work loss following methods used to study the impact of cost-sharing and medical spending. To do so, we analyze a unique database containing quarterly employee-level data reports of lost work time (absence hours and short term disability days) and cost-sharing amounts. One underlying concern is that, at a point in time, prescription drug benefit generosity may be positively correlated with generosity of absence and short-term disability benefits. Employees in plans with lower prescription drug cost-sharing (more generous) may also receive larger (more generous) allocations of absence and disability benefits, which will create an omitted variable bias suggesting lower prescription drug cost sharing is related to more absence and disability days. Because absence and disability benefits are very stable over time we address 
this concern by estimating fixed effects models, focusing on the longitudinal relationship between changes in cost-sharing and lost work time. We estimate these models on two cohorts of employees undergoing treatment for pain, where changes in cost-sharing, health, and healthcare utilization are likely to be quickly realized in terms of lost work time.

We report two main findings. First, we find a positive association between cost-sharing and hours absent, which, though the effect is small in percentage terms, has large fiscal implications. Second, we find no such association between cost-sharing and the probability of incurring shortterm disability days.

The paper proceeds as follows. We describe our approach and then describe the characteristics of the medication class and its relationship to work loss. Next, we describe our methods and provide a detailed overview of our estimation strategy. Following are results, and in the final section we offer some conclusions.

Framework

Employers offering health benefits to their employees usually proffer a limited number of health plans to employees residing in a geographic area. Each health plan available to the employees within an employer (which we refer to as an employer-health plan or plan) provides a set of covered benefits at a level of cost-sharing to plan enrollees. Our aim is to analyze the relationship between prescription drug cost-sharing and work loss in the reduced form. We do not identify a mechanism connecting cost-sharing and work loss, but are estimating the magnitude and statistical significance of the relationship between plan generosity (an important benefit management tool for employers) and time lost from work that may stem from differences 
in adherence to medication or changes in care-seeking behavior. We focus on the marginal costs of services to the employee (e.g., copayments or coinsurance) because deductibles for prescription drugs are somewhat uncommon in general and are quite rare in our data set.

We construct a panel data set with employees as the cross sectional unit and calendar quarters as the unit of time. In each quarter, an employee is also mapped into an employer-health plan, and cost-sharing amounts for the employer-health plan are recorded on each observation in the data set. Employees can change plans over time (though this is rare) so they do not fully nest within employer-health plans. This creates a three-level, multilevel model (quarter, employee, employer-health plan) and we address this directly in our estimation approach.

In cross-sections, employers offering more generous medical benefits may also offer more generous absence or short-term disability benefits (or may differ in other ways), which may explain why the cross-sectional relationship observed between cost-sharing and time lost from work is negative (i.e., employees with lower levels of cost-sharing report a greater number of absences and/or disability days). We focus on the effects of changes in cost-sharing on changes in absence and disability using a fixed effect model. If the resulting association between an increase in cost-sharing and work loss is positive, then plans reducing the generosity of prescription drug benefits experience increases in absence and/or work loss.

\section{Pain Management}

Pain medications (analgesics) are some of the most commonly prescribed medications in the United States. From 2005-2008 when ranked in terms of the percentage of adults using a prescription drug in the medication class, pain medications ranked second after antidepressants 
for adults 18-44 (5.1\% of adults) (National Center for Health Statistics 2011). Similarly, for adults 45-64 years pain medications ranked third after antihyperlipidemic agents and antidepressants with $14.0 \%$ filling a prescription for a pain medication.

Pain and painful conditions are associated with high rates of absence and work days lost. In a random sample of 28,902 workers in the United States in 2001-2002, 57.2\% reported a common painful condition in the previous two weeks (e.g., headache, arthritis, back pain, other) and 7.2\% reported two or more hours of time lost from work due to a painful condition (Stewart et al. 2001). Disease exacerbations and pain control are also related to work loss. Almost one fourth of workers with arthritis currently experiencing a pain exacerbation reported lost productive time from work, compared to $13.1 \%$ with arthritis who were not experiencing a pain exacerbation (Ricci et al. 2005).

While many pain medications are over the counter or available in generic form, many others are brand name and are often indicated when pain management and control is an issue. We focus on two cohorts of patients prescribed brand name non-steroidal anti-inflammatory drugs (NSAID) and opiod pain medications. The first is employees with a diagnosis of a chronic medical condition that is marked by significant pain (the chronic pain cohort). Chronic pain diagnoses include osteoarthritis, fibromyalgia, rheumatoid arthritis and neuropathic pain. Second, as a sensitivity analysis we include all employees meeting the selection criteria, regardless of diagnosis (All diagnosis cohort).

We selected pain management as our condition of interest as it is an immediate phenomenon these medications work in hours or days and have a short half-life. Also, pain and work 
productivity have strong ties; therefore, within the two cohorts changes in medication utilization or care-seeking would be likely to manifest in the short-term in changes in hours lost from work.

Methods

\section{Data Source}

Information from the Truven Health MarketScan Health and Productivity Management Database was used for this study. The database contains health insurance claims for inpatient, outpatient, and pharmaceutical services for enrollees from employer-sponsored health plans offered by approximately 150 medium and large-sized firms in the United States. For a subset of these firms, medical claims data are supplemented with productivity management information for two types of lost work time: absence hours and short term disability days. The absence and short term disability data sets are, for the most part, mutually exclusive.

\section{Study Population}

Employees were eligible for inclusion in the study if they were between the ages of 18 and 64, were continuously enrolled for at least 7 quarters between January 1, 2006 and December 31, 2008, filled a prescription for pain medication, and had no indication of pregnancy throughout the study time frame. Employees enrolled in high-deductible plans, or comprehensive pain management programs were excluded because of broader effects of those programs that could not be measured.

Within the study time frame, the date of first fill in the medication class was assigned as the index date for each employee. Employees were followed until December 31, 2008 or through 
the last complete calendar quarter prior to disenrollment, must have been active employees on the index date, and must have been continuously enrolled for at least 1 year prior to the index date to measure preindex health status and at least 3 calendar quarters after. To exclude patients with a single episode of pain, employees also had to have a second pharmacy claim in the medication class during the 2 months following the index fill date. We excluded the first (index) quarter observed for each employee, as the first quarter is most likely to be endogenous with worker absence or disability.

\section{Measures of Lost Work Time}

Two types of lost work time were calculated per quarter throughout the study time frame, hours absent and days of short term disability for each employee. The information is recorded in the personnel time management systems of the employers. Hours of absence represented the sum of hours recorded for all short-term absence types (e.g., vacation, personal and sick time) since employees may trade off hours recorded for each type of absence (e.g., using vacation time for sick leave). In addition, some of the employers grant employees a bank of hours of leave from work that does not distinguish between types of absence. Our approach allows pooling of absence information across employers.

Short-term disability days represent the number of days in each calendar quarter that the employee received short-term disability benefits while they were unable to work. Very few employees utilize this benefit (5-10\% of the employees in our sample in a quarter), therefore, we estimated receipt of short term disability benefits as a dichotomous outcome.

\section{Estimation}


Our data set contains three dimensions of variation: time (calendar quarters), employees, and employer-health plans. Because the error components may be correlated with the observed explanatory variables, we estimate the parameters using a fixed effects three-way error components model (Abowd, Kramarz and Margolis, 1999; Andrews, Schank and Upward, 2006).

In the linear form we consider the following model:

$Y_{i t}=x_{i t} \beta+w_{P(i, t) t} \gamma+u_{i} \eta+q_{P(i, t) \rho}+\alpha_{i}+\phi_{p}+\mu_{t}+\varepsilon_{i t}$

Where $\mathrm{i}$ indexes employees, $\mathrm{t}$ indexes time in calendar quarters, and $\mathrm{p}$ indexes employer-health plans. $Y_{i t}$ is the dependent variable. Both employees and plans are assumed to enter and exit the panel resulting in an unbalanced panel with $\mathrm{T}_{\mathrm{i}}$ observations per employee and $\mathrm{N}^{*}=\Sigma \mathrm{T}_{\mathrm{i}}$ employee-quarters in total. The fixed effects are $\alpha_{i}$ for the employee, $\phi_{p}$ for the plan and $\mu_{t}$ for time. We assume $\varepsilon_{i t}$ is strictly exogenous. Terms $x_{i t}$ and $u_{i}$ are vectors of observable employee covariates. $w_{P(i, t) t}$ and $q_{P(i, t)}$ are vectors of observable plan covariates and are indexed with $\mathrm{P}(\mathrm{i}, \mathrm{t})$ as employees can change plans over time (employees do not fully nest within plans). P(i,t) maps employee i to plan P at time t. Each unique employee*employer-health plan combination in the data set denotes a 'spell' of plan enrollment, which is indexed with s.

Both $\alpha_{i}$ and $u_{i}$ are time invariant for employees and $\phi_{p}$ and $q_{P(i, t)}$ are fixed over time for plans. $x_{i t}$ varies over $\mathrm{i}$ and $\mathrm{t}$ and $w_{P(i, t) t}$ varies across $\mathrm{p}$ and $\mathrm{t}$, although the data are collected at the i,t level, therefore plan covariates also vary at the i,t level. 
The explanatory variable of interest, the prescription drug cost sharing amount, is in $\gamma$. We can obtain consistent estimates of $\beta$ and $\gamma$ by time demeaning within each employee-plan spell. We define the spell-level heterogeneity as:

$\lambda s \equiv \alpha_{i}+u_{i} \eta+\phi_{p}+q_{P(i, t) \rho}$

Substituting (2) into (1)

$Y_{i t}=x_{i t} \beta+w_{P(i, t) t} \gamma+q_{P(i, t)} \rho+\lambda s+\mu_{t}+\varepsilon_{i t}$

Within each employee-plan spell, the spell level heterogeneity, $\lambda s$, does not vary and can be removed by subtracting averages at the spell level. We assume that $u_{t}$ are fixed and are estimated directly using time dummies (hence, not reflected in the next equation).

$\left(Y_{i t}-\right.$ Ybar $\left._{s}\right)=\left(x_{i t}-x b a r_{s}\right) \beta+\left(w_{P(i, t) t}-w_{b a r}\right) \gamma+\left(\varepsilon_{i t}-\varepsilon b a r_{s}\right)$

To examine the relationship between cost-sharing and absence hours we first estimate an OLS model with time fixed effects and standard errors corrected for possible correlation within employee over time (Model I-OLS). Because we do not include spell fixed effects, this model is identified, in part, by differences across employers and will suffer from bias associated with unobserved generosity of absence and disability benefits, but it serves as a useful benchmark.

We then estimate Equation (4) fitting a three-way fixed effect model with spell-level fixed effects, time fixed effects, and standard errors corrected for possible correlation within employee over time (Model II-OLS Spell Fixed Effects). 
Since absence hours are recorded as counts, as a comparison we also estimate the three-way fixed effects model in Equation (4) with a conditional ML Poisson regression (with a log link and robust standard errors) using the same covariates (Model III - Poisson Spell Fixed Effects).

We estimate two linear probability models for use of short term disability: OLS (analogous to Model I) and OLS Spell Effects (analogous to Model II).

We estimate each of these models for two cohorts of employees: those with chronic pain diagnoses and the larger cohort of employees including all patients treated for pain, regardless of diagnosis of chronic pain.

Explanatory Variables

The key explanatory variable is the patient cost-sharing amount imposed by the employer-plan for the medication class of interest. This is based on the average cost-sharing amount in dollars (i.e., copayment, coinsurance) per prescription (standardized to a 30-day supply) for medications in the medication classes (ie, brand name NSAIDs and opiods). Employer-plan cost-sharing is represented in each calendar quarter as patients are likely to respond to the prices they face, even if they do not fill a prescription within that class.

Sociodemographic variables included age in years, gender, urban (versus rural) area of residence, median household income (from the Census Bureau based on ZIP code of residence), percent college graduates (based on ZIP codes), US census region (Northeast, North Central, West, and South), and the hourly/salaried status of the employee. 
Two health-status measures were also included and were calculated in the 12 months of continuous enrollment prior to the index date. The Deyo Charlson Comorbidity Index (CCI) accounts for the effects of comorbid conditions based on the presence of ICD-9-CM codes in the health care claims (D’Hoore et al. 1996). Psychiatric Diagnostic Groupings (PDG) were also accounted for in this study during the pre-index period. The PDGs measure the presence of psychiatric or substance dependent conditions. There are 12 possible PDGs, which are aggregated from ICD-9-CM diagnosis codes (Ashcraft et al. 1989). Examples include alcohol use disorders and other substance use disorders, depression, bipolar disorder, post-traumatic stress disorders, and schizophrenia.

All models include an array of time fixed effects representing each calendar quarter (with 2Q2006 as the reference quarter).

Results

We found 4,763 employees filling prescriptions for pain medication meeting the selection criteria who also had absence information and 20,273 employees meeting the selection criteria who had short-term disability data (Table 1). About one quarter of these employees $(1,495$ with absence information and 6,144 with short term disability information) had a diagnosis of chronic pain (osteoarthritis, fibromyalgia, rheumatoid arthritis or neuropathic pain). Within these four groups, patients had relatively similar characteristics. Approximately two thirds were age 45 and older and about $60 \%$ were male. Reflecting the composition of the data contributors, the South region was most prevalent, representing $40-46 \%$ of the employees, and the vast majority lived in an urban residence (over $88 \%$ ). The mean CCI score was less than 0.5 , indicating that the average comorbidity burden was less than 1 condition per employee. The average PDG score 
was below 0.25 , indicating that the number of psychiatric comorbidities was less than 1 per employee.

Table 2 contains additional descriptive statistics about the employee cohorts, including the two main measures of interest: absence hours and the percent of employees using short-term disability benefits in a quarter. On average, employees with chronic pain recorded 76.7 hours of absence, and employees with all diagnoses had five fewer hours of absence on average. Shortterm disability use rates were $10.25 \%$ for employees with chronic pain and were 4 percentage points lower for employees with all diagnoses.

Results from the absence hours models for the chronic pain cohort (those with a diagnosis of a condition associated with chronic pain) with largely cross-sectional identification (OLS estimates I) revealed that the coefficient of cost-sharing is negative $(\mathrm{p}<0.01)$ (Table 3a), reinforcing our concern that employers with less generous cost-sharing policies (higher cost sharing) may also have less generous absence benefits (and thus fewer absences).

However, when focusing on the longitudinal variation in prescription drug generosity, we find a positive association: rising cost-sharing amounts were associated with increases in absence hours. In the linear, three-way, spell-level fixed effect model (II) a \$1 increase in copayments was associated with $0.470(\mathrm{p}=0.004)$ additional hours of absence, and the magnitude of the effect was similar in the Poisson model (III). This suggests a price elasticity of absence of about 0.16 .

Results from the absence hours models for the all diagnosis cohort (those treated for pain, regardless of diagnosis) were similar to those of the chronic pain cohort. The cross-sectional model revealed an inverse relationship between cost sharing and absence $(p<0.05)$. In the linear 
spell-level fixed effects model the estimated effect size was smaller than the estimates in the narrower chronic pain cohort, but retained statistical significance ( 0.342 additional hours of absence, $\mathrm{p}<0.01)$. Finally, the Poisson spell-level fixed effects model yielded a positive, statistically significant coefficient $(\mathrm{p}<0.01)$ with a similar effect size in this cohort. This suggests a price elasticity of absence of about 0.12 .

Unlike the absence hour models, in the cross-sectional short term disability models the coefficient on cost-sharing was positive and not statistically significant (Table 4). When adding spell-level fixed effects to the model, the results were less pronounced than the absence models and none reached statistical significance.

\section{Effect Size}

While we do not attempt to estimate the structural relationships, we are able to estimate the financial impact of foregone medication use on productivity based on estimates of adherence and days supply per prescription. In Table 5 we display predicted values associated with a $\$ 5$ increase in cost sharing per prescription (about 20\%). In our fixed effects models, the number of absence hours per calendar quarter also rises by approximately 1 hour (in the OLS model, chronic pain cohort) to 2.4 hours (Poisson model, chronic pain cohort). This corresponds to approximately $1.3 \%-3.1 \%$ change in absence hours. Using methods analogous to our analysis of absences, we estimate a demand elasticity for utilization of pain medications within each cohort (not shown) of about -0.35 (within the range reported in the literature) (Goldman et al. 2004; Gibson et al. 2005). Accordingly, with a $20 \%$ increase in copayment of $\$ 5$, we expect a $7 \%$ drop in prescriptions. Therefore, because the average number of brand name pain 
prescriptions per person per quarter was 0.5 , we estimate about 0.035 foregone prescriptions/ person/ quarter $(0.5$ prescriptions $*-7 \%)$. Combining our estimates of foregone prescriptions (converted to days supply lost based on a 30 day prescription) and our estimates of increased absences, we estimate that 1 hour lost of absence (1/8 of a day, or $12 \%)$ is associated with 1.05 days supply lost (0.035 foregone prescriptions * 30 days supplied per prescription). Thus, our estimates imply that if an employee in chronic pain does not take these medications for one day, the employee has a $1 / 8$ chance ( $12 \%$ chance) of missing a day's work ( $8 \mathrm{hrs})$.

Though the effect size in hours is modest, the fiscal consequences may be large. If we assume that a $\$ 5$ increase in cost-sharing $(20 \%)$ is associated with a 1 hour increase in absence $(\sim 1.3 \%)$ this would be valued at $\$ 42 /$ hour fully loaded with fringe benefits (workers in private industry, large establishments) (BLS 2012). Alternatively, the average hourly earnings for Americans overall is about $\$ 31$ loaded. The $\$ 31-\$ 42 / \mathrm{hr}$ in absence-related costs would offset any employer savings associated with raising copayments.

Those savings, from the perspective of the employer and assuming no wage offset, would consist of $\$ 5$ per prescription filled (now paid by the worker not the firm) and the employer costs associated with foregone prescriptions. In our sample, employees average about 0.5 brand name pain medication prescriptions/ person/ quarter (so the employer saves \$2.50).

Given our estimate of .035 foregone prescriptions/ person if we estimate the employer cost of prescriptions at $\$ 100$ per prescription (the high end of the range in our data, we estimate a savings of $\$ 3.50$ ). Combining this with $\$ 2.50$ associated with the cost shift on inframarginal prescriptions, yields a savings of $\$ 6.00 /$ person per quarter, which is small relative to the 
productivity costs. If we assume full wage offset, the societal cost would be only the cost of the foregone prescription (employer and employee share) which would be even smaller than $\$ 6.00$.

However, the calculation of savings is imprecise for several reasons. It likely overstates the effects as productivity losses are unlikely to amount to 1-2 full hours as an employee may work from home when sick, or other employees may perform additional work duties for the absent employee. Yet even if the effective hours of work lost is only 20 minutes (a third of an hour), the productivity loss is still large relative to the savings.

More importantly, this calculation focuses on a single medication class, and the patient is typically on multiple classes of medication. On average these patients fill a total of 5.6 prescriptions per quarter in addition to brand name pain medications. This would increase the savings from $\$ 6$ to $\$ 60$ (if overall elasticity is -.35 ). This exceeds the productivity costs, but the productivity costs still offset about half of these savings. Moreover, the total savings associated with higher copayments are lower than estimated above because we omit any increased medical spending due to less use of medications, which in other cases have been estimated to be nontrivial (Roebuck et al. 2011; Sokol 2005, Chandra, Gruber, McKnight 2010). Thus while there is a lot of uncertainty associated with the full financial effects of copayment increases, which is not our focus, the magnitude of the productivity costs seems meaningful in comparison to the medical costs.

Diagnostic checks 
Fixed effect models remove the cross-sectional variation and the effects of time invariant observables, identifying effects based on variation in cost-sharing changes over time. The strong assumption inherent in our identification strategy is that trends in outcomes are similar in plans that changed cost-sharing (prior to the cost sharing change) and plans that did not change costsharing. We compared trends in outcomes (absence and short term disability) in the quarters prior to the cost-sharing change for the two thirds of plans that eventually changed their costsharing to trends in outcomes for plans that did not change cost-sharing. This comparison was made by regressing outcomes on an indicator for plans that changed their cost-sharing, a time trend and the interaction of the two, controlling for clustering over time by plan. We found that there were no significant differences in the absence or disability time trends for plans that eventually increased copayments (prior to the copayment change) and those that did not (for absence hours, coefficient $=-0.85 \mathrm{p}=0.561$ and for any short-term disability days, coefficient $=$ $-0.002 \mathrm{p}=0.194$

To address concerns of omitted time varying variables--where cost sharing may be changing at the same time as other aspects of compensation or sick days, or where cost sharing may be changing at the same time as other employee characteristics are changing--we first correlated changes in prescription drug copayments and changes in medical office visit copayments to determine if prescription drug and medical benefits moved in concert. The correlation between changes in medical copayments and prescription drug copayments was near zero (-0.02 for employees with absence data and 0.03 for employees with short term disability data), reflecting that the structure of prescription drug benefits was often carved out from other health benefits. We also analyzed two measures of health status, the Charlson Comorbidity Index and Psychiatric 
Diagnostic Groupings, each measured in each quarter of the data. We then regressed changes in copay on changes in each of these health status measures in separate regressions and found no significant relationship between changes in health status and changes in cost-sharing.

In addition, if employees with lower health status that have a choice choose lower copayments, these employees may also be more likely to be absent. However, there was little choice of prescription drug plan benefits in these firms, most prescription drug benefits were similar across medical plans for a given employee, and our results sign in the opposite direction. If selection on health status is occurring our results are most likely biased downward.

We performed two additional sets of sensitivity analysis. First, we included a measure of benefit generosity in the non-drug medical benefit (the plan-level percentage of total payments borne by employees) and the results were similar. Second, we removed the two health status measures (CCI and PDG) from the covariates and the coefficients of the models were almost identical to those presented here.

\section{Discussion}

Previous research on the effects of prescription drug copayments has focused on the impact of higher copayments on the utilization of prescription drugs and other medical services. Yet, because prescription drugs are an important part of chronic disease management, their effects may impact broader aspects of patients' lives. One area of particular importance is worker productivity. Our analysis, focused on workers with chronic pain, confirms that higher copayments are associated with more absences from work, but effects on short-term disability are not statistically significant. Often lost in the discussion about medical pain management is 
attainment of appropriate levels of use of pain medications through sufficient limits and supports to maintain productivity (US FDA 2012). Medications should be taken according to the physician's instructions, and not exceeding the prescribed dosage or frequency.

The intent of our study was not to conduct a full cost accounting associated with raising copayments or to make policy recommendations. Instead we addressed the more focused question about whether changes in medication use might affect productivity, focusing on a patient group where effects are likely to be manifest quickly. The effects and effect sizes may not be similar to other condition cohorts. We focused on active workers with chronic pain, who may differ substantially from other patients with chronic pain as they continued to participate in the workforce. Now that we have found a modest, though fiscally meaningful, effect within this patient cohort, future research focusing on other conditions and exploring structural relationships should be considered and evaluations of health policy changes should strive to integrate productivity effects when possible. 
Acknowledgment

Funding for this study was provided by Pfizer Inc. to Truven Health Analytics (formerly Thomson Reuters Healthcare). All opinions expressed are those of the authors. We thank Amanda Farr, MPH for research and programming assistance. 
References

Abowd, J, Kramarz, F \& Margolis, D. High wage workers and high wage firms. Econometrica 67, 251-333.1999.

Afendulis CC and Chernew ME. State-level impacts of Medicare Part D. American Journal of Managed Care. 17(Supp 2). 2011.

Andrews M, Schank T, and Upward R. Practical fixed-effects estimation methods for the threeway error-components model. The Stata Journal. 6(4). 2006.

Ashcraft MLF, Fries BE, Nerenz DR, et al. A psychiatric patient classification system: an alternative to diagnosis-related groups. Medical Care. 1989;27:543-557.

Bureau of Labor Statistics. National Compensation Survey: Employee Benefits in the United States, March 2011. http://www.bls.gov/ebs/benefits/2011/ebbl0048.pdf. Extracted July $\underline{26}, 2012$.

Bureau of Labor Statistics. US Department of Labor. Employer costs for employee compensation-March 2012. Available at: www.bls.gov/ect. Published June 7, 2012.

Carls GS, Roebuck MC, Brennan TB, Slezak JA, Matlin OS, Gibson TB. Impact of medication adherence on absenteeism and short-term disability for five chronic diseases. Journal of Occupational and Environmental Medicine. 2012 Jul;54(7):792-805.

Chandra A, Gruber J, McKnight R. Cost-Sharing and Hospitalization Offsets In the Elderly. American Economic Review. 100(1): 193-213. March 2010.

D'Hoore W, Bouckaert A, Tilquin C. Practical considerations on the use of the Charlson Comorbidity Index with administrative data bases. Journal of Clinical Epidemiology. 1996;49:1429-1433.

Garrett B and Buettgens M. Employer-Sponsored Insurance under Health Reform: Reports of Its Demise Are Premature. January 2011 http://www.rwjf.org/files/research/71749.pdf. Accessed January 1, 2012.

Gibson TB, Mark TL, Axelsen K, Baser O, Rublee DA, McGuigan KA. Impact of Statin Copayments on Adherence and Medical Care Utilization and Expenditures. American Journal of Managed Care. 12(Spec): SP11-19. December 2006. 
Gibson TB, Ozminkowski RJ, Goetzel RZ. The effects of prescription drug cost sharing costsharing: a review of the evidence. Am J Manag Care 2005;11:730-740.

Gibson TB, Song X, Alemayehu B, Wang S, Waddell J, Bouchard J, Forma F. Cost-Sharing, Adherence, and Health Outcomes in Patients with Diabetes. American Journal of Managed Care. 16(8): 589-600. August 2010.

Goldman DP, Joyce GF, Escarce JJ, Pace JE, Solomon MD, Laouri M, Landsman PB, Teutsch SM. Pharmacy benefits and the use of drugs by the chronically ill. JAMA. 2004;291(19):2344-50.

Goldman DP, Joyce GF, Zheng Y. Drug Cost Sharing: Cost-sharing: Associations with Medication and Medical Utilization and Spending and Health, JAMA. 2007;298(1):6169.

Kaiser Family Foundation/Health Research \& Educational Trust. Employer Health Benefits: 2011 Annual Survey. www.kff.org. Accessed January 1, 2012.

Loeppke R, Haufle V, Jinnett K, Parry T, Zhu J, Hymel P, Konicki D. Medication adherence, comorbidities, and health risk impacts on workforce absence and job performance. $\mathrm{J}$ Occup Environ Med. 2011 Jun;53(6):595-604.

National Center for Health Statistics. Health ,United States 2010: With Special Feature on Death and Dying. Table 95. Hyattsville, MD 2011.

Ricci JA, Stewart WF, Chee E, Leotta C, Foley K, Hochberg MC. Pain exacerbation as a major source of lost productive time in US workers with arthritis. Arthritis Rheum. 2005 Oct 15;53(5):673-81.

Roebuck MC, Liberman JN, Gemmill-Toyama M, Brennan TA. Medication adherence leads to lower health care use and costs despite increased drug spending. Health Aff (Millwood). 2011 Jan;30(1):91-9.

Sokol MC, McGuigan KA, Verbrugge RR, Epstein RS. Impact of Medication Adherence on Hospitalization Risk and Healthcare Cost. Med Care. 2005 Jun; 43(6):521-30. 
Stewart WF, Ricci JA, Choo E, Morganstein D, Lipton R. Lost Productive Time and Cost Due to Common Pain Conditions in the US Workforce. JAMA. November 12, 2001 290(18): 2445-2454.

US Food and Drug Administration. A Guide to Safe Use of Pain Medications. 2012. Extracted June 26, 2012. http://www.fda.gov/forconsumers/consumerupdates/ucm095673.htm. 
Table 1 - Employee Characteristics

\begin{tabular}{|c|c|c|c|c|c|c|c|c|c|c|c|c|}
\hline \multirow[b]{4}{*}{ Age Group (\%) } & \multicolumn{5}{|c|}{ Employees with Absence Data } & & \multicolumn{6}{|c|}{ Employees with Short Term Disability Data } \\
\hline & \multicolumn{3}{|c|}{ Chronic Pain Diagnosis } & \multirow{2}{*}{\multicolumn{2}{|c|}{$\begin{array}{r}\text { All Diagnoses } \\
4,763\end{array}$}} & & \multicolumn{3}{|c|}{ Chronic Pain Diagnosis } & \multirow{2}{*}{\multicolumn{2}{|c|}{$\begin{array}{r}\text { All Diagnoses } \\
20,273 \\
\end{array}$}} & \\
\hline & \multicolumn{3}{|c|}{1,495} & & & & \multicolumn{3}{|c|}{6,144} & \\
\hline & & & & & & & & & & & & \\
\hline 18-34 years & \multicolumn{3}{|c|}{$3.5 \%$} & \multicolumn{3}{|c|}{$8.8 \%$} & \multicolumn{3}{|c|}{$5.2 \%$} & \multicolumn{3}{|c|}{$10.1 \%$} \\
\hline $35-44$ years & \multicolumn{3}{|c|}{$18.0 \%$} & \multicolumn{3}{|c|}{$22.1 \%$} & \multicolumn{3}{|c|}{$18.4 \%$} & \multicolumn{3}{|c|}{$23.7 \%$} \\
\hline $45-54$ years & \multicolumn{3}{|c|}{$46.6 \%$} & \multicolumn{3}{|c|}{$44.1 \%$} & \multicolumn{3}{|c|}{$45.7 \%$} & \multicolumn{3}{|c|}{$42.1 \%$} \\
\hline $55-64$ years & \multicolumn{3}{|c|}{$31.9 \%$} & \multicolumn{3}{|c|}{$25.0 \%$} & \multicolumn{3}{|c|}{$30.7 \%$} & \multicolumn{3}{|c|}{$24.1 \%$} \\
\hline Female $(\%)$ & \multicolumn{3}{|c|}{$40.3 \%$} & \multicolumn{3}{|c|}{$33.7 \%$} & & $41.0 \%$ & & \multicolumn{3}{|c|}{$37.1 \%$} \\
\hline \multicolumn{13}{|l|}{ Employee Status } \\
\hline Hourly & & $14.4 \%$ & & & $13.8 \%$ & & & $29.8 \%$ & & & $23.7 \%$ & \\
\hline Salaried & & $54.1 \%$ & & & $53.1 \%$ & & & $31.4 \%$ & & & $34.8 \%$ & \\
\hline Unknown & & $31.6 \%$ & & & $33.1 \%$ & & & $38.8 \%$ & & & $41.5 \%$ & \\
\hline Census Region $(\%)$ & & & & & & & & & & & & \\
\hline North East & & $10.6 \%$ & & & $13.4 \%$ & & & $11.0 \%$ & & & $13.4 \%$ & \\
\hline North Central & & $21.6 \%$ & & & $17.7 \%$ & & & $33.6 \%$ & & & $28.2 \%$ & \\
\hline South & & $40.2 \%$ & & & $42.0 \%$ & & & $42.6 \%$ & & & $45.9 \%$ & \\
\hline West & & $27.6 \%$ & & & $26.9 \%$ & & & $12.8 \%$ & & & $12.5 \%$ & \\
\hline Urban Residence (\%) & & $94.5 \%$ & & & $94.4 \%$ & & & $88.9 \%$ & & & $89.3 \%$ & \\
\hline Sociodemographic Information (Census Bureau) & & ean & Std & & & Std & & & Std & & ean & Std \\
\hline Median Household Income (000s) & $\$$ & 52.30 & (16.08) & $\$$ & 52.02 & (16.38) & $\$$ & 50.33 & (17.57) & $\$$ & 51.55 & $(18.12)$ \\
\hline Percent College Graduates & & 0.283 & $(0.15)$ & & 0.279 & $(0.14)$ & & 0.255 & $(0.15)$ & & 0.271 & $(0.16)$ \\
\hline Health Status & & & & & & & & & & & & \\
\hline Charlson Comorbidity Index & & 0.421 & $(0.91)$ & & 0.333 & $(0.80)$ & & 0.464 & $(0.96)$ & & 0.345 & $(0.85)$ \\
\hline Number of Psychiatric Diagnostic Groupings & & 0.223 & $(0.56)$ & & 0.170 & $(0.49)$ & & 0.244 & $(0.64)$ & & 0.179 & $(0.52)$ \\
\hline
\end{tabular}


Table 2 - Distribution of Cost Sharing Index and Work Loss Measures

\begin{tabular}{lccccc}
\hline & \multicolumn{3}{c}{ Employees with Absence Data } \\
& Chronic Pain Diagnosis & All Diagnoses \\
\hline Employees (n) & 1,495 & & \multicolumn{2}{c}{4,763} & \\
Employer-Plans (n) & 106 & & & 137 & \\
Employee*Employer-Plan Spells (n) & 1,668 & & & 5,289 & \\
Employee Quarter Observations (n) & 11,113 & & 31,328 & \\
& Mear & Std & Mean & Std \\
Prescription Drug Cost-Sharing Amount & $\$ 26.39$ & $(8.95)$ & $\$ 26.68$ & $(8.98)$ \\
Change in Cost-Sharing & $\$ 0.38$ & $(3.78)$ & $\$$ & 0.32 & $(4.00)$ \\
Absence Hours & 76.69 & $(73.39)$ & 71.60 & $(69.53)$ \\
Quarters Observed per Employee & 7.4 & & & 6.6 &
\end{tabular}

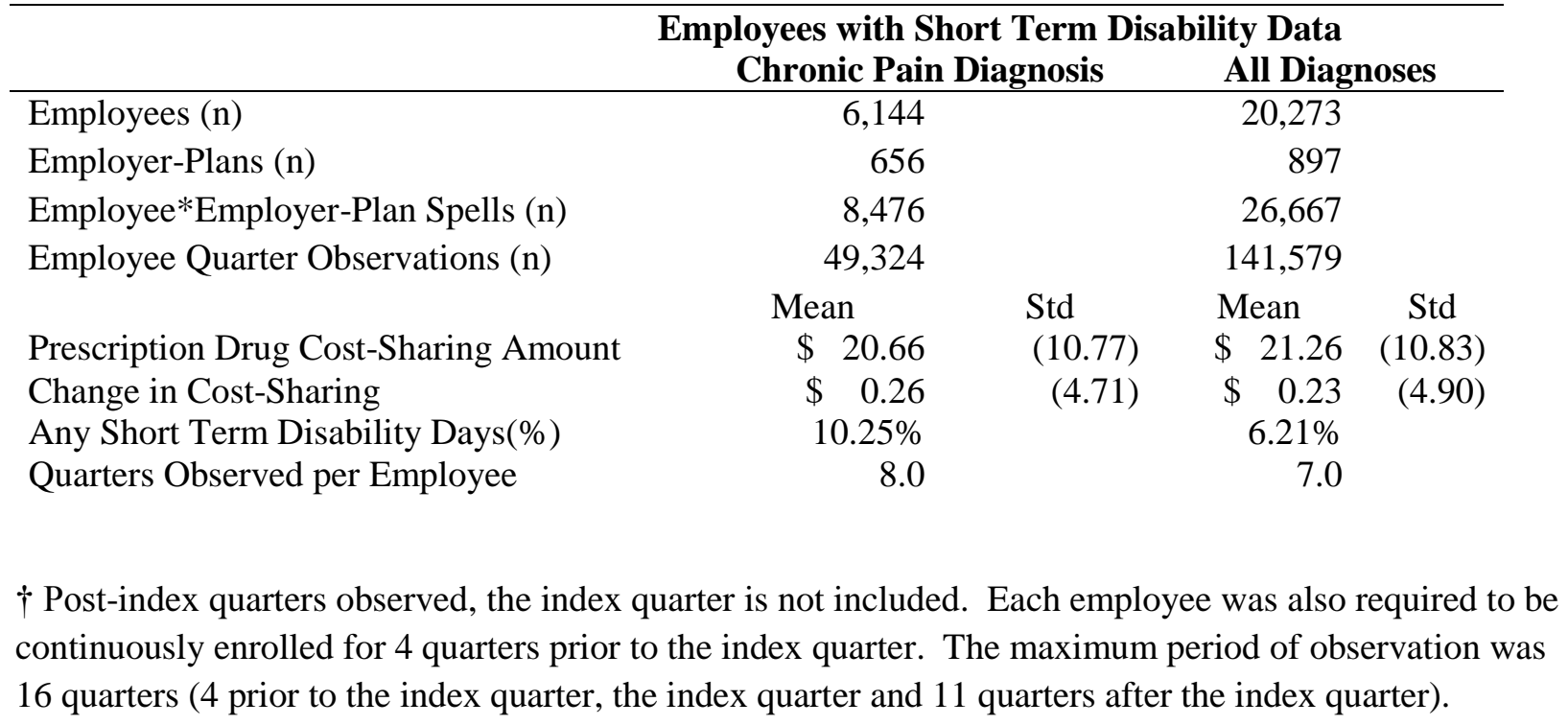


Table 3a-Coefficients of Estimates, Absence Hours Chronic Pain Diagnosis ( $\mathrm{n}=1,495$ Employees)

\begin{tabular}{|c|c|c|c|c|c|c|}
\hline & \multirow[t]{2}{*}{$\begin{array}{l}\text { OLS } \\
\text { (I) } \\
\text { Coef. }\end{array}$} & \multirow[b]{2}{*}{$\mathrm{p}$} & \multicolumn{2}{|c|}{$\begin{array}{l}\text { OLS } \\
\text { Spell Fixed Effects } \\
\quad \text { (II) }\end{array}$} & \multicolumn{2}{|c|}{$\begin{array}{l}\text { Poisson } \\
\text { Spell Fixed Effects } \\
\quad \text { (III) }\end{array}$} \\
\hline & & & Coef. & $\mathrm{p}$ & Coef. & $\mathrm{p}$ \\
\hline Prescription Drug Cost Index(\$) & -1.488 & 0.000 & 0.470 & 0.004 & 0.007 & 0.003 \\
\hline \multicolumn{7}{|l|}{ Age Groups $(\operatorname{Ref}=$ Age $45-54)$} \\
\hline Age 1834 & -24.531 & 0.000 & 24.480 & 0.024 & 0.575 & 0.038 \\
\hline Age3544 & -7.728 & 0.021 & 6.470 & 0.044 & 0.100 & 0.035 \\
\hline Age5564 & 0.287 & 0.923 & 0.091 & 0.981 & 0.000 & 0.994 \\
\hline Female & 2.007 & 0.449 & (omitted) & & (omitted) & \\
\hline Hourly & 24.588 & 0.000 & 5.721 & 0.611 & 0.061 & 0.697 \\
\hline Salary & -9.091 & 0.002 & -3.135 & 0.762 & -0.061 & 0.631 \\
\hline \multicolumn{7}{|l|}{ Census Region (Ref=South) } \\
\hline North Central & -7.954 & 0.018 & 4.334 & 0.135 & 0.089 & 0.071 \\
\hline North East & 13.383 & 0.003 & -6.722 & 0.017 & -0.125 & 0.006 \\
\hline West & 13.024 & 0.000 & 20.203 & 0.000 & 0.109 & 0.077 \\
\hline Urban & 5.760 & 0.374 & -55.883 & 0.249 & -0.512 & 0.195 \\
\hline Household Ince & 0.174 & 0.088 & 0.099 & 0.598 & 0.002 & 0.540 \\
\hline Percent Colleg & -26.994 & 0.011 & 14.929 & 0.482 & 0.111 & 0.751 \\
\hline Charlson Come & -0.994 & 0.373 & (omitted) & & (omitted) & \\
\hline PDGs & 1.752 & 0.439 & (omitted) & & (omitted) & \\
\hline \multicolumn{7}{|l|}{ Calendar Quarter $(\operatorname{Ref}=2 \mathrm{Q} 2006)$} \\
\hline 3Q2006 & 9.542 & 0.001 & 7.572 & 0.007 & 0.128 & 0.007 \\
\hline 4Q2006 & -0.208 & 0.945 & -2.107 & 0.476 & -0.037 & 0.493 \\
\hline 1Q2007 & 7.748 & 0.013 & -5.668 & 0.051 & -0.096 & 0.062 \\
\hline 2Q2007 & 17.185 & 0.000 & -6.224 & 0.034 & -0.053 & 0.268 \\
\hline 3Q2007 & 33.768 & 0.000 & 10.336 & 0.001 & 0.152 & 0.002 \\
\hline 4Q2007 & 34.688 & 0.000 & 14.431 & 0.000 & 0.195 & 0.000 \\
\hline 1Q2008 & 7.456 & 0.024 & -9.033 & 0.001 & -0.103 & 0.034 \\
\hline 2Q2008 & 11.270 & 0.001 & -6.289 & 0.021 & -0.072 & 0.126 \\
\hline 3Q2008 & 29.178 & 0.000 & 10.684 & 0.000 & 0.156 & 0.001 \\
\hline 4Q2008 & 40.302 & 0.000 & 25.173 & 0.000 & 0.314 & 0.000 \\
\hline Constant & 87.741 & 0.000 & 97.106 & 0.029 & & \\
\hline
\end{tabular}


Table 3b - Coefficients of Estimates Absence Hours All Diagnoses ( $\mathrm{n}=6,029$ Employees)

\begin{tabular}{|c|c|c|c|c|c|c|}
\hline & \multirow{2}{*}{$\begin{array}{l}\text { OLS } \\
\text { (I) } \\
\text { Coef. }\end{array}$} & \multirow[b]{2}{*}{$\mathrm{p}$} & \multicolumn{2}{|c|}{$\begin{array}{l}\text { OLS } \\
\text { Spell Fixed Effects } \\
\quad \text { (II) }\end{array}$} & \multicolumn{2}{|c|}{$\begin{array}{l}\text { Poisson } \\
\text { Spell Fixed Effects } \\
\quad \text { (III) }\end{array}$} \\
\hline & & & Coef. & $\mathrm{p}$ & Coef. & $\mathrm{p}$ \\
\hline Prescription Drug Cost Index $(\$)$ & -1.260 & 0.000 & 0.342 & 0.000 & 0.006 & 0.000 \\
\hline \multicolumn{7}{|l|}{ Age Groups $(\operatorname{Ref}=A g e$ 45-54) } \\
\hline Age1834 & -18.434 & 0.000 & 3.392 & 0.436 & 0.059 & 0.487 \\
\hline Age3544 & -8.311 & 0.000 & 0.462 & 0.816 & 0.007 & 0.835 \\
\hline Age5564 & 2.074 & 0.255 & 2.039 & 0.436 & 0.029 & 0.414 \\
\hline Female & 1.635 & 0.262 & (omitted) & & & 0.802 \\
\hline Hourly & 30.073 & 0.000 & 0.344 & 0.962 & -0.025 & 0.238 \\
\hline Salary & -5.929 & 0.000 & -6.629 & 0.320 & -0.119 & 0.299 \\
\hline \multicolumn{7}{|l|}{ Census Region (Ref=South) } \\
\hline North Central & -9.208 & 0.000 & 30.971 & 0.116 & 0.912 & 0.569 \\
\hline North East & 7.459 & 0.001 & -1.236 & 0.902 & -0.082 & 0.247 \\
\hline West & 14.175 & 0.000 & 18.404 & 0.053 & 0.218 & 0.204 \\
\hline Urban & 11.855 & 0.001 & -15.236 & 0.251 & -0.243 & 0.861 \\
\hline Household In & 0.105 & 0.048 & -0.019 & 0.868 & 0.000 & 0.646 \\
\hline Percent Colle & -22.133 & 0.000 & 12.950 & 0.433 & 0.119 & 0.000 \\
\hline Charlson Comorbidity Index & 1.171 & 0.257 & (omitted) & & & 0.085 \\
\hline PDGs & 3.079 & 0.035 & (omitted) & & & 0.001 \\
\hline \multicolumn{7}{|l|}{ Calendar Quarter (Ref=2Q2006) } \\
\hline 3Q2006 & 9.716 & 0.000 & 7.796 & 0.000 & 0.139 & 0.020 \\
\hline 4Q2006 & -0.996 & 0.598 & -3.107 & 0.081 & -0.060 & 0.000 \\
\hline 1Q2007 & 5.496 & 0.004 & -5.360 & 0.002 & -0.108 & 0.000 \\
\hline 2Q2007 & 12.168 & 0.000 & -6.766 & 0.000 & -0.072 & 0.000 \\
\hline 3Q2007 & 31.742 & 0.000 & 12.436 & 0.000 & 0.185 & 0.030 \\
\hline 4Q2007 & 29.864 & 0.000 & 13.576 & 0.000 & 0.198 & 0.000 \\
\hline 1Q2008 & 3.674 & 0.062 & -8.763 & 0.000 & -0.111 & 0.000 \\
\hline 2Q2008 & 7.235 & 0.000 & -5.021 & 0.003 & -0.068 & 0.000 \\
\hline 3Q2008 & 25.117 & 0.000 & 12.627 & 0.000 & 0.187 & 0.000 \\
\hline 4Q2008 & 33.502 & 0.000 & 23.832 & 0.000 & 0.321 & 0.000 \\
\hline Constant & 74.199 & 0.000 & 61.285 & 0.000 & & \\
\hline
\end{tabular}


Table 4 - Coefficients of Estimates, Any Short Term Disability Days (\%)

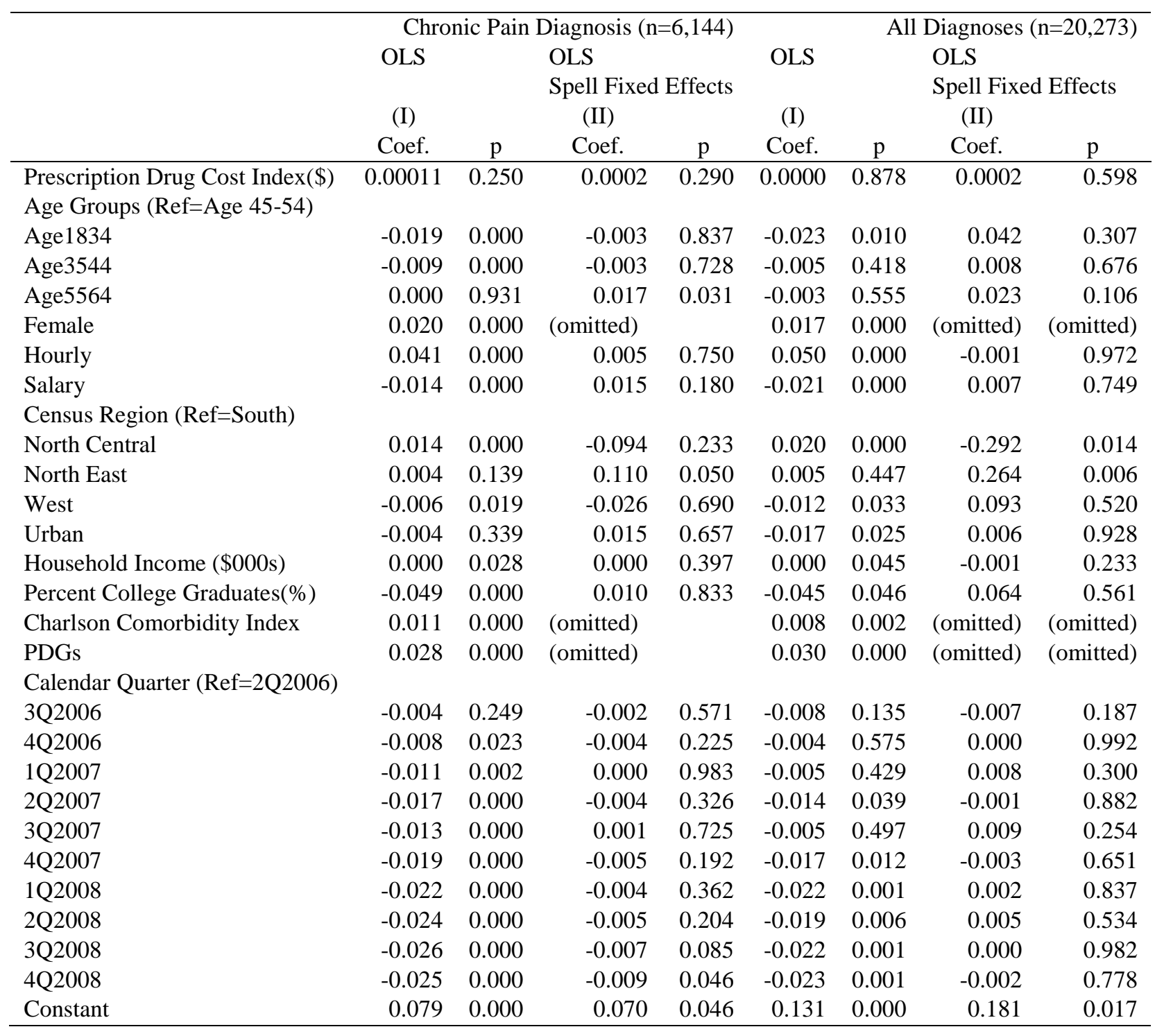


Table 5 - Predicted Increase in Absence Hours per Calendar Quarter with a \$5 Increase in Cost Sharing

\begin{tabular}{lrrrrr}
\hline & \multicolumn{2}{c}{$\begin{array}{l}\text { OLS } \\
\text { Mean }\end{array}$} & \multicolumn{2}{l}{$\begin{array}{l}\text { Poisson } \\
\text { Spell Fixed Effects }\end{array}$} & \multicolumn{2}{c}{$\begin{array}{l}\text { Spell Fixed Effects } \\
\text { (III) }\end{array}$} \\
& Absence Hours & $\begin{array}{c}\text { (II) } \\
\text { Difference }\end{array}$ & \% Difference & Difference & $\%$ Difference \\
\hline Chronic Pain Diagnosis & 76.69 & 2.35 & $3.06 \%$ & 1.04 & $1.35 \%$ \\
All Diagnoses & 71.60 & 1.71 & $2.39 \%$ & 1.03 & $1.44 \%$ \\
\hline
\end{tabular}

